RUNNING HEAD: ADOLESCENT ATTITUDES TOWARD WIFE BEATING IN JORDAN

Attitudes toward Wife Beating among Female and Male Adolescents in Jordan Isabell Schuster $^{\text {a }}$, Pelin Gul ${ }^{\text {b }}$, Manuel Eisner ${ }^{\mathrm{c}}$, and Lana Ghuneim ${ }^{\mathrm{d}}$

${ }^{a}$ Department of Education and Psychology, Free University of Berlin, Germany ${ }^{\mathrm{b}}$ Department of Psychology, Health \& Technology, University of Twente, Netherlands

${ }^{\mathrm{c}}$ Institute of Criminology, University of Cambridge, United Kingdom ${ }^{\mathrm{d}}$ School of Law, University of Sheffield, United Kingdom

Correspondence address:

Isabell Schuster

Free University of Berlin

Department of Education and Psychology

Schwendenerstraße 33

D-14195 Berlin, Germany

Telephone: $+49-3083868619$

E-mail: isabell.schuster@fu-berlin.de

Author note: During the analysis and first manuscript writing phase, Isabell Schuster was affiliated with the University of Potsdam, Germany. During the revision phase, she was affiliated with the Free University of Berlin, Germany. 


\begin{abstract}
Previous research in the Middle East and North Africa has revealed justifying attitudes toward wife beating among adults but little is known about adolescent attitudes and its predictors. Therefore, the purpose of the present study was to examine theoretically relevant predictors of supportive attitudes toward wife beating among adolescents in Jordan. Due to limited evidence on the role of gender, potential differences between girls and boys were explored. A total of 856 students (455 female) from 14 secondary schools in Amman, the capital city of Jordan, participated in the cross-sectional study which was conducted during normal school hours. Religiosity, beliefs regarding control of female sexuality, moral neutralization of aggression, and parental harsh discipline were assessed to predict attitudes toward wife beating, controlling for socio-demographic variables. Acceptance rates of justification for wife beating ranged between $6.1 \%$ and $50.5 \%$. Hierarchical regression analysis showed that beliefs supporting control of female sexuality, moral neutralization of aggression, and paternal harsh discipline predicted supportive attitudes toward wife beating, but religiosity and maternal harsh discipline did not. Separate analyses for each gender yielded that maternal harsh discipline was a significant predictor of wife beating attitudes for girls, but not for boys, whereas paternal harsh discipline was a significant predictor for boys, but not for girls. Furthermore, beliefs regarding female sexuality and moral neutralization of aggression mediated the relationship between religiosity and wife beating attitudes. Policy measures and intervention efforts targeting particularly harsh discipline and sociocultural beliefs are sorely needed to address this issue in Jordanian society.
\end{abstract}

Keywords: Wife beating attitudes, predictors, adolescents, Jordan, MENA region 


\section{Attitudes toward Wife Beating among Female and Male Adolescents in Jordan}

Aggression against women in general and wife beating in particular are serious social problems, often accompanied by severe physical and psychological health consequences (Akyüz, Yavan, Şahiner, \& Kılıç, 2012; Heise, Ellsberg, \& Gottemoeller, 2002). International victimization surveys estimate that between $20 \%$ and $30 \%$ of women experience physical aggression by an intimate partner at least once in their lifetime (e.g., FRA - European Union Agency for Fundamental Rights, 2015). Although wife beating is considered a worldwide problem, especially high prevalence rates have been documented in the Middle East and North Africa (WHO, 2013; for a review, see Boy \& Kulczycki, 2008). In particular, deficiencies in legal protection and a lack of education campaigns and support networks for victims aggravate women's situation (Obeid, Chang, \& Ginges, 2010). Previous research on wife beating in the Middle East and North Africa has examined its prevalence (e.g., AlModallal, Zayed, Abujilban, Shebab, \& Atoum, 2015; Al-Nsour, Khawaja, \& Al-Kayyali, 2009) and beliefs and attitudes (e.g., Haj-Yahia, 1998a, 1998b, 2002, 2005; Obeid et al., 2010), using mainly all-female adult samples (Boy \& Kulczycki, 2008). However, there is a paucity of data assessing female and male adolescent attitudes toward wife beating and its predictors. Addressing this gap, the purpose of this study was to examine a set of predictors of wife beating attitudes derived from different theoretical perspectives among both female and male adolescents in Jordan and to identify some of the potential underlying mechanisms. This, in turn, may help to develop evidence-based interventions for adolescents which are aimed at reducing their justifying attitudes toward wife beating.

\section{Prevalence and Justification of Wife Beating in Jordan}

Jordan is an Arabic country in the MENA (Middle East and North Africa) region, with Amman as its capital. The Jordanian society is characterized by strong gender inequality, conservative gender roles, and patriarchal family structures, with women and 
children in subordinated positions (Al-Badayneh, 2012; United Nations Development Programme, 2018). The rigid gender roles are also reflected in the low female labor force participation rate of $14.0 \%$ compared to $63.7 \%$ of men (United Nations Development Programme, 2018).

Regarding the recognition of domestic violence at the legal level, a big step was taken in 2008 by introducing the Law on Protection from Domestic Violence No. 6, offering some protection to victims, including penalties for perpetrators, though it did not consider domestic violence to be a criminal act. More recently, in 2017, this law has been replaced by the Law on Protection from Domestic Violence No. 15, allowing for more protective measures and also criminalizing the most serious assaults. However, despite these laws against domestic violence, alarmingly high prevalence rates of physical aggression against women by an intimate partner were revealed by several studies. For example, the Jordan Population and Health Survey 2012, a nationally representative study of ever-married women, showed that $21.8 \%$ of the female participants reported physical violence by their husband (Department of Statistics \& ICF International, 2013). Even higher rates were yielded in a clinic-based survey in which $43 \%$ of the women reported moderate and $36 \%$ of the women reported severe physical violence by their intimate partner (Spencer, Shahrouri, Halasa, Khalaf, \& Clark, 2014), demonstrating that wife beating is a severe problem in the Jordanian society.

A major concern is that a substantial proportion of both men and women in the MENA countries believe that intimate partner violence is justified in certain circumstances (for a review, see Boy \& Kulczycki, 2008). According to the Jordan Population and Health Survey $2012,69.9 \%$ of ever-married women agreed to at least one justification of wife beating, with the most prominent justification being that the wife has relationships with other men (65.4\%), followed by insulting the husband (38.1\%; Department of Statistics \& ICF International, 2013). Similar results were found in a study conducted with Jordanian men, 
with $70.2 \%$ of the participants believing that beating is justified if the wife does not respect the husband's parents or siblings (Haj-Yahia, 2005). What is also noteworthy is that many men and women do not only believe that violence against women is justified under certain circumstances, but they also have the false beliefs that women benefit from beating and that it is the women's fault (for an overview, see Boy \& Kulczycki, 2008). In contrast to extrafamilial violence which is publicly recognized and not accepted, wife abuse is considered a private matter, not requiring social or legal intervention (Douki, Nacef, Belhadj, Bouasker, \& Ghachem, 2003).

Although studies have shown that a substantial proportion of adult men and women in the MENA region justify wife beating, to date, data on attitudes toward wife beating among adolescents is scarce. Notably, according to the Jordan Population and Health Survey 2012, the highest overall acceptance rate of wife beating (84.1\%) was observed among young women aged between 15 and 19 years (Department of Statistics \& ICF International, 2013), highlighting the need to closely study adolescent attitudes. Given that adolescence is a developmental stage when children go through a process of individuation whereby they try to form their own identity (Kroger, 2007), it is crucial to identify factors which contribute to supportive attitudes toward wife beating early in the developmental trajectory, as findings can inform evidence-based interventions to reduce intimate partner violence in the future.

\section{Theoretical Framework and Predictors of Wife Beating Attitudes}

Aggression against women, particularly wife beating and related justifying attitudes, is a complex, multidimensional issue, and an extensive body of past studies has shown that one theory is not sufficient to explain justifying attitudes nor actual aggressive behavior (cf., Haj-Yahia \& Uysal, 2011; Heise, 1998). Hence, there is a need to combine different theoretical perspectives into an integrative framework because this may allow a more elaborate understanding of the complex phenomena of wife beating attitudes. Building on 
previous research (see, for example, Haj-Yahia \& Btoush, 2018; Haj-Yahia \& Uysal, 2011), we examined predictors of wife beating attitudes that are based on these three theoretical perspectives: (1) patriarchal ideology, (2) social learning theory, and (3) social cognition. These three theoretical perspectives were chosen as there is evidence that each of them may explain to some extent why individuals justify wife beating. In the present study, patriarchal ideology is represented by beliefs regarding control of female sexuality and religiosity; social learning theory is represented by parental harsh discipline; and social cognition is represented by moral neutralization of aggression. In the following, these theoretical perspectives, the related variables derived, and the connection between these variables are explained in detail.

Patriarchal ideology. From a feminist perspective, it is argued that patriarchy, referring to a social system characterized by social and economic power imbalance between women and men, is the root for the existence and persistence of violence against women (see Ali \& Naylor, 2013, for an overview). Patriarchal ideology in this view refers to beliefs, norms, and attitudes that justify this male dominance (Yllö \& Straus, 1990). Societies in the MENA region are strongly characterized by patriarchal ideology and patrilineal family systems which reinforce male privilege and control over resources, including women's sexuality and reproductive value (Kulwicki, 2002). These family systems are sustained by strict gender-specific norms that expect women to be submissive, obedient to men, preserve their chastity, restrain their sexuality, and have no or little contact with the opposite sex until marriage (Kulwicki, 2002; Oberwittler \& Kasselt, 2014).

The notions that female sexuality should be suppressed and controlled predominate the Jordanian society and also are linked to the views that women are deserving of men's beating and that violence against women is acceptable, especially when women fail to live by these cultural expectations (Haj-Yahia, 2002, 2005). For instance, studies conducted with Palestinians found that between $23 \%$ and $71 \%$ of men and between $13 \%$ and $69 \%$ of women 
expressed support for wife beating on certain occasions, including when a wife has been sexually unfaithful, when she has refused to have sex with the husband, when she disobeyed the husband, and when she challenged the husband's manhood (Haj-Yahia, 1998a, 1998b). In the present study, we measured adolescents' beliefs regarding control of female sexuality which entail notions about the inappropriateness of girls being on their own with somebody from the other sex. We hypothesized that adolescents who endorse beliefs regarding control of female sexuality would be more likely to justify wife beating.

Furthermore, it has been argued that most mainstream religions can be considered patriarchal institutions (e.g., Crittenden \& Wright, 2013). In line with this notion, studies in MENA countries have shown that higher religiosity was associated with patriarchal beliefs (Zaatut \& Haj-Yahia, 2016), which, in turn, were linked to justifying wife beating attitudes (Haj-Yahia, 2003). Based on these findings, we hypothesized that higher religiosity would predict more supportive attitudes toward wife beating. Additionally, we explored whether beliefs regarding control of female sexuality would mediate the relationship between religiosity and wife beating attitudes. As higher religiosity has been associated with more conservative sexual attitudes (Duyan \& Duyan, 2005) and greater sexual morality concerns (Krakow et al., 2015), religious individuals' more supportive attitudes toward wife beating may be primarily due to their beliefs supporting control of female sexuality. Hence, we expected that higher religiosity would be associated with more supportive attitudes toward wife beating, mediated through stronger beliefs supporting control of female sexuality.

Social learning theory. According to the social learning theory (Bandura, 1977), aggressive behavior and attitudes condoning such behavior are learned through socialization processes starting in early childhood. Witnessing and experiencing violence within the family may contribute to the view that using violence is appropriate to solve conflicts. In addition, 
the parents' behavior serves as a role model so that the child or adolescent is more likely to behave in a similar way (O’Leary, 1988).

Past studies with adult samples have revealed a positive relationship between the exposure to family violence in childhood and adolescence and the endorsement of wife beating and pro-violence attitudes. For instance, Haj-Yahia and Uysal (2008) found that experiencing physical and verbal aggression by parents was linked to more justifying attitudes toward wife beating among college students in Turkey. Similarly, Herrenkohl, Huang, Tajima, and Whitney (2003) showed that harsh parental discipline was associated with more pro-violence attitudes among adolescents and young adults. Furthermore, there is also evidence to suggest that attitudes toward wife beating among adolescents may be shaped by the experience of parental violence as well. For example, in their study conducted with male adolescents, Dalal, Lee, and Gifford (2012) have shown that the exposure to family violence was associated with greater justification of wife beating in India. Focusing on another form of violence against women, Eisner and Ghuneim (2013) have found a positive relationship between paternal harsh discipline and attitudes in support of honor killing of women among male, but not female adolescents. Maternal harsh discipline, however, had no significant influence, on either boys or girls (Eisner \& Ghuneim, 2013).

Similar to previous research (e.g., Herrenkohl et al., 2003), in the present study, we measured parental harsh discipline as a predictor of attitudes toward wife beating. Building on previous findings, we expected that the exposure to parental harsh discipline would be associated with more supportive attitudes toward wife beating. Furthermore, based on social learning theory and previous evidence suggesting that harsh discipline by the mother and by the father may differentially influence male and female adolescents (e.g., Eisner \& Ghuneim, 2013), we assessed maternal and paternal harsh discipline separately to explore their potentially different effects on wife beating attitudes among male and female adolescents. 
Social cognition. Support of wife beating exemplifies a series of justifications of why and under which situations it may be justifiable for a man to hit his wife. Such attitudes may be connected to a wider set of beliefs that legitimate the use of physical aggression against others in general. To examine this, we concentrate on the concept of moral neutralization of aggression (Ribeaud \& Eisner, 2010). Moral neutralization is based on different social cognitive concepts: (1) moral disengagement (Bandura, 2002), (2) neutralization theory (Sykes \& Matza, 1957), and (3) self-serving cognitive distortions (Barriga \& Gibbs, 1996). It denotes to a set of instruments by which an individual justifies aggressive behavior toward others, comprising, for example, notions that the victim is to blame for the aggression, that the victim deserves being abused, and that other people would do the same.

Although social cognitive processes in general and moral neutralization of aggression in particular have not been examined as predictors of wife beating attitudes before, Eisner and Ghuneim (2013) found that Jordanian adolescents who morally neutralize aggression were more likely to report attitudes in support of honor crimes. Hence, we hypothesized that adolescents who morally neutralize aggression would be more likely to justify wife beating. In addition, we explored whether moral neutralization of aggression would mediate the relationship between religiosity and wife beating attitudes. Given that most religions emphasize peace, interpersonal harmony, and moral values, religious participation may promote "moral expertise" (Rossano, 2008). Based on this understanding, we expected a negative association between religiosity and moral neutralization of aggression. In turn, higher religiosity would be associated with less supportive attitudes toward wife beating, mediated through lower moral neutralization of aggression.

\section{Socio-Demographic Correlates of Attitudes toward Wife Beating}

A number of studies have revealed that some socio-demographic variables are linked to attitudes toward wife beating. In particular, having lower education levels (Zaatut \& Haj- 
Yahia, 2016) and having more than one child (Dhaher, Mikolajczyk, Maxwell, \& Krämer, 2010) were associated with support of wife beating. To account for these potential differences, we used education, family size, and family structure as control variables in the present study.

\section{The Current Study}

Past research has demonstrated that a substantial proportion of men and women in MENA countries condone wife abuse and battering. However, it is largely unclear if predictors of wife beating attitudes established in adult samples would hold as predictors of adolescent attitudes. Evidence to that effect would further strengthen the theoretical conceptualization of predictors identified in previous research. Hence, the present study intends to make a major step forward by examining adolescent attitudes toward wife beating using a theoretically relevant set of potential predictors in the context of Jordanian society. As previous research pointed out that no single theory can completely explain wife beating attitudes, in the present study, we integrated three theoretical perspectives to examine wife beating attitudes. At the level of patriarchal ideology, we examined beliefs regarding control of female sexuality and religiosity. At the level of social learning theory, we examined maternal and paternal harsh discipline. Finally, at the level of social cognitions, we examined moral neutralization of aggression. We hypothesized that stronger support for controlling women's sexuality, higher religiosity, more harsh discipline by the father and by the mother, and greater moral neutralization of aggression would predict more supportive attitudes toward wife beating, while controlling for socio-demographic variables.

Given that most previous research on attitudes toward wife beating used all-female samples (Boy \& Kulczycki, 2008), only limited data on men's attitudes toward wife beating is available. In addition, the limited available data on gender differences revealed inconsistent findings, with some studies showing more supportive attitudes toward wife beating among 
men than women (e.g., Obeid et al., 2010) and others showing no gender differences (e.g., Haj-Yahia, Sousa, Alnabilsy, \& Elias, 2015). Therefore, in this study, we explored whether the general acceptance of wife beating as well as the predictors of attitudes toward wife beating differ between adolescent boys and girls.

Finally, to better understand the role of religiosity in wife beating attitudes, we explored whether religiosity would be indirectly associated with adolescents' supportive attitudes towards wife beating through beliefs favoring control of female sexuality and moral neutralization of aggression. We hypothesized that higher religiosity would be related to stronger support for controlling women's sexuality but to less moral neutralization of aggression, suggesting differential mediating effects of the two variables.

\section{Method}

\section{Participants}

A total of 14 secondary schools were purposely targeted to participate in the study and yielded a sample of 856 ninth grade students (455 female; 53.2\%). The schools were all located in the capital city, Amman, but included different student bodies with different socioeconomic backgrounds. The majority of the schools (12 of 14) were single-gender schools, and two were mixed. Ten schools (429 participants; 50.1\%) were private schools, and four schools (427 participants) were public schools with a student body of lower socio-economic status. Hence, our sample is more likely to represent adolescents of middle-class background because only $30 \%$ of secondary school students in Amman attend private schools (Nuffic, 2017). All students in the classrooms gave consent to participate in the study. Their ages ranged from 14 to 16 years, with a mean age of 14.6 years $(S D=0.56)$. With respect to religion, the majority of the respondents (90.4\%) self-identified as Muslims, $9.0 \%$ as Christians, $0.2 \%$ as Druze, and $0.4 \%$ reported that they are not religious.

\section{Measures}


Attitudes toward wife beating. To measure the participants' rationalization of wife beating, we used a shortened version of Haj-Yahia's (2003) valid and reliable scale for measuring beliefs about wife beating, which is a revised version of the Inventory of Beliefs about Wife Beating (IBWB; Saunders, Lynch, Grayson, \& Linz, 1987). Haj-Yahia's original scale comprised 23 items but not all of them were appropriate for ninth grade students, which is why we only used 13 items (e.g., "Occasional violence by a husband toward his wife can help maintain the marriage.”). Responses were made on a seven-point scale that ranged from 1 (strongly disagree) to 7 (strongly agree). Cronbach's alpha was .87.

Beliefs regarding control of female sexuality. To measure beliefs regarding control of female sexuality, a six-item scale was developed by the authors. Participants were asked to consider how wrong they find it to be for a girl of their age to, for example, "fall in love", "be friends with a boy", or "choose her future husband herself". A four-point response scale was provided, ranging from 1 (not wrong at all) to 4 (very wrong). Cronbach's alpha was .86.

Religiosity. A scale of seven items was created to assess the importance of religion in one's life (e.g., "I try hard to carry my religion over into all my other dealings in life"). Responses were given on a four-point scale, ranging from 1 (strongly disagree) to 4 (strongly agree). Cronbach's alpha was .71.

Parental harsh discipline. Adopting measures from previous research (e.g., McKee et al., 2007), parental harsh discipline was measured with three items each, separately for the mother and the father. Students were asked how often their mother or father "shouted at", "slapped", or "hit" them. Answers were given on a five-point scale that ranged from 1 (never) to 5 (very often). The Cronbach's alphas were .74 for paternal harsh discipline and .67 for maternal harsh discipline scales.

Moral neutralization of aggression. To measure the extent to which participants justify aggressive behavior, we used 15 items from the moral neutralization scale developed 
by Ribeaud and Eisner (2010) for which criterion and convergent validity was established. An example item is "Many problems can be solved with violence". Responses were made on a four-point scale that ranged from 1 (strongly disagree) to 4 (strongly agree). The scale had a Cronbach's alpha of .83.

Demographic information. All participants were asked about their gender (male vs. female), parental education, family size, family structure, and religion. Regarding parental education, participants were asked to indicate the highest level of their mother's and father's education each on a six-point scale $(1=$ no schooling to $6=$ completed post-graduate studies). Mother's and father's education level were summed to a score of the parental educational level. To assess family size, participants were asked to report the number of siblings using an open-ended format. Responses were dichotomized $(0=$ small family, $1=$ large family) at the median. $44.7 \%$ of the respondents had four or more siblings and were coded as a "large family". For traditional family structure, participants were asked to indicate their mother's occupational status on a five-point scale $(1=$ unemployed, $2=$ self-employed, 3 = full-time employed, 4 = part-time employed, $5=$ retired $)$, which was then turned into a dichotomized scale $(0=$ non-traditional, $1=$ traditional $)$. If the mother was a housewife $(76.8 \%)$ or retired $(1.1 \%)$, the family structure was coded as "traditional". If the mother was employed, meaning that she contributed to the financial provision of the family and did not fulfill the traditional domestic role of a housewife only, the family structure was coded as "non-traditional".

\section{Procedure}

First, the study was reviewed and approved internally by the Department of Criminology, University of Cambridge. Second, the permission to carry out the study and an approval of the study items were obtained from the Jordanian Ministry of Education. In a third step, the headmasters of the schools were contacted to grant permission for the study. 
The survey was conducted during normal school hours, and the students were informed that the study would investigate their attitudes towards different situations and practices. In addition, it was explained that participation is voluntary and all responses are confidential and anonymous. The students took about 45 minutes to complete the questionnaires, while one of the study researchers was present along with their classroom teacher to help answer any questions they would have. There was a $100 \%$ response rate as all students present in the classrooms have consented to take part in the study. No incentives were provided.

Asking children, adolescents, but also adults about sensitive topics, such as experiences of violence and attitudes toward violence, may trigger negative emotions or may have an impact on future social interactions. Hence, ethical considerations have to be taken into account seriously. Several empirical studies on violence-related topics (e.g., experience of violence) addressed this issue, showing that the majority of participants described their participation in the study as positive or beneficial (e.g., Ellonen \& Pösö, 2011). However, it is important to follow guidelines of good practice to ensure that no harm is caused by participating in research. In the current study, anonymity and confidentiality was ensured and both the teacher and researcher were available to talk about any concerns.

With respect to translation, as proposed by Hambleton and Kanjee (1995), a translator who had excellent knowledge of both languages and who was familiar with social science research and the culture to be studied, translated the scales from English to Arabic. Subsequently, the preliminary translation was sent to two other Arabic/English speakers to be reviewed, enabling a careful and culture-sensitive translation.

\section{Analytic Plan}

There was only little missing data $(1.8 \%$ or less on the key variables). Assuming a missing at random (MAR) mechanism, the missing data were handled by listwise deletion. To predict wife beating attitudes, hierarchical regression analyses were conducted. Statistics of 
collinearity suggested its absence. For the mediation analysis, Hayes' (2017) PROCESS macro for SPSS was used as it facilitates the testing of mediators in parallel as well as the examination of indirect effects. To test the significance of the indirect effects, $95 \%$ confidence intervals were calculated through 5,000 bias-corrected bootstrap replications.

\section{Results}

\section{Prevalence of Agreement with Wife Beating}

Analyses at the item-level showed that a substantial proportion of adolescent girls and boys justify wife beating. As presented in Table 1 , between $6.1 \%$ and $50.5 \%$ of the participants agreed or strongly agreed that it is okay for a man to beat his wife under certain circumstances. For instance, wife beating was mostly accepted (50.5\%) when the wife was unfaithful. Gender differences were found in 11 of the 13 items with boys having a greater tendency to justify wife beating than girls. Female and male adolescents did not differ in their justifying attitudes towards wife beating in cases of when a wife's behavior challenges her husband's manhood and when she breaks agreements she has made with him.

$$
\text { [Table } 1 \text { near here] }
$$

\section{Descriptive Statistics}

Means and standard deviations of all key variables as well as bivariate correlations are depicted in Table 2. A multivariate analysis of variance (MANOVA) was conducted to examine gender differences in wife beating attitudes and the predictor variables. Scores of justification of wife beating, beliefs regarding control of female sexuality, paternal harsh discipline, and moral neutralization of aggression were significantly higher among boys than girls. No gender differences were found for religiosity and maternal harsh discipline. With respect to bivariate correlations (see also Table 2), attitudes toward wife beating were positively correlated with beliefs regarding control of female sexuality, harsh discipline by 
both the mother and the father, and moral neutralization of aggression, whereas the correlation with religiosity was nonsignificant.

[Table 2 near here]

\section{Prediction of Wife Beating Attitudes}

To examine our hypotheses, we conducted a hierarchical linear regression, controlling for relevant socio-demographic variables (gender, parental education, family size, and traditional family structure) in the first step and introducing the predictors (beliefs regarding control of female sexuality, religiosity, maternal and paternal harsh discipline, moral neutralization of aggression) in the second step. The results are presented in Table 3.

[Table 3 near here]

The first step of the model was significant, $F(4,816)=74.91, p<.001$. Male sex, having parents with a lower education level, living in a large family, and traditional family structure were associated with more supportive attitudes toward wife beating. The addition of the second step contributed to a significant change and a significant overall model, $F(9,811)$ $=47.18, p<.001$. All socio-demographic variables remained significant in the second step. As expected, higher support for controlling female sexuality, more harsh discipline by the father, and greater moral neutralization of aggression were associated with a higher tendency to justify wife beating. In contrast to expectations, religiosity and harsh discipline by the mother were not significant in shaping attitudes toward wife beating.

Whether the predictors of wife beating attitudes differ between boys and girls was examined in additional regression analyses separately for each gender group. Results of these analyses are also presented in Table 3. Similar patterns were found for the socio-demographic variables, beliefs regarding control of female sexuality, religiosity, and moral neutralization of aggression. However, harsh discipline by the mother was a significant positive predictor of girls' supportive attitudes toward wife beating, but not of boys. In contrast, harsh discipline 
by the father was a significant positive predictor of boys' supportive attitudes toward wife beating, but not of girls.

In addition, we explored whether beliefs regarding control of female sexuality and moral neutralization of aggression would mediate the relationship between religiosity and wife beating attitudes, controlling for gender, parental education, family size, and traditional family structure. As shown in Figure 1, both the direct and total effects of religiosity on wife beating attitudes were nonsignificant. However, higher religiosity was indirectly linked to more supportive attitudes toward wife beating via greater support for controlling female sexuality $(B=.12, S E=.03,95 \% \mathrm{CI}[.08, .18])$. In addition, higher religiosity was linked to less supportive attitudes toward wife beating via lower moral neutralization of aggression $(B$ $=-.08, S E=.02,95 \% \mathrm{CI}[-.14,-.05])$, confirming our exploratory hypotheses.

[Figure 1 near here]

\section{Discussion}

There is evidence that supportive attitudes toward wife beating are highly prevalent among adult men and women in Jordan (e.g., Department of Statistics \& ICF International, 2013; Haj-Yahia, 2005), whereas data on adolescent attitudes is scarce. To address this gap, the purpose of the present study was to examine a combined set of predictors of attitudes toward wife beating derived from three theoretical perspectives among male and female adolescents in Jordan. Because previous data on gender similarities and differences are limited and inconsistent, we also explored potential differences in the prediction of wife beating attitudes as a function of gender.

With respect to the acceptance of wife beating, prevalence rates ranged between $6.1 \%$ and $50.5 \%$ in the total sample. Dalal et al. (2012) who used nationally representative samples of male adolescents found similar acceptance rates of wife beating in India (51\%) and Bangladesh (42\%) but a lower rate in Nepal (28\%). Regarding data from Jordan, the 
representative Jordan Population and Health Survey 2012 (Department of Statistics \& ICF International, 2013) revealed higher rates than those reported in the present study, particularly among 15 to 19 -years-olds. It is noteworthy that in the present study, the highest approval rate was found for the wife being unfaithful (50.5\%). This finding is also in line with previous research, where wife beating was considered an appropriate punishment for infidelity (e.g., Department of Statistics \& ICF International, 2013; Haj-Yahia, 2003; Zaatut \& Haj-Yahia, 2016). Particularly in Jordan or other countries in the MENA region, being unfaithful as a wife is considered a strong violation of sexuality norms, damaging the husband's honor and bringing shame to the family, and can even lead to honor killings (Kulwicki, 2002). Our findings suggest that these norms are already internalized among 14 to 16-year-old Jordanian adolescents.

Regarding gender differences, boys held more supportive attitudes toward wife beating than did girls. This is consistent with a study conducted among Lebanese college students, which found that men were more likely to condone wife beating than were women (Obeid et al., 2010). Although comparative data on males' attitudes as well as potential gender differences in wife beating attitudes is lacking (Boy \& Kulczycki, 2008), our findings align with gender differences found in attitudinal research on other forms of violence against women (e.g., Alzoubi \& Ali, 2018; Lowe, Khan, Thanzami, Barzy, \& Karmaliani, 2018). This gender difference may be due to the different perspectives because boys may respond from the perspective of a potential perpetrator and girls from the perspective of a potential victim.

Within an integrative theoretical framework, the main goal of the present study was to examine the role of beliefs regarding control of female sexuality, religiosity, parental harsh discipline, and moral neutralization of aggression on attitudes toward wife beating, while controlling for relevant socio-demographic variables. Regarding the control variables, 
consistent with previous research (e.g., Dalal et al., 2012; Dhaher et al., 2010; Zaatut \& HajYahia, 2016), lower parental education, large family size, and traditional family structure were all associated with more supportive attitudes toward wife beating.

With respect to the predictors, male and female adolescents who reported greater support for controlling female sexuality were more likely to justify wife beating. This finding is consistent with previous evidence which has shown that beliefs regarding the importance of female chastity and sexual purity play an important role in justification and tolerant perceptions of intimate partner violence (Vandello \& Cohen, 2008). Even though females, compared to males, are less approving of violence against women, recent studies confirm that in patriarchal societies, females, similar to their male counterparts, also endorse the abuse of women. For example, Jordanian male and female adolescents who more strongly believed in the importance of female chastity were more likely to support honor killings (Eisner \& Ghuneim, 2013).

In contrast to our prediction, religiosity was not directly associated with attitudes toward wife beating. This finding was also inconsistent with previous research that has revealed a positive correlation between the two constructs (e.g., Haj-Yahia, 2005). However, indirect effects from religiosity to wife beating attitudes were found through support for control of female sexuality and moral neutralization of aggression. On the one hand, higher religiosity was associated with more supportive attitudes toward wife beating through greater support for controlling female sexuality; on the other hand, higher religiosity was associated with less supportive attitudes toward wife beating through lower moral neutralization of aggression. Although this different function of religiosity may seem contradictory at first, previous studies, mostly in the field of sexual behavior and aggression, have shown that religiosity may be conceptualized as both a protective and a risk factor (Schuster \& Krahé, 2019; Smith, 2015). Given that most religions emphasize prosocial norms and decline 
aggression, this mechanism may reduce the moral neutralization of aggression and, in turn, supportive attitudes toward violence. At the same time, higher religiosity was associated with greater support for controlling female sexuality, being in line with previous findings that linked religiosity to sexual morality concerns (Krakow et al., 2015) and conservative sexual attitudes (Duyan \& Duyan, 2005). Hence, higher religiosity also indirectly predicted more supportive attitudes toward wife beating through stronger beliefs regarding control of female sexuality.

Regarding parental harsh discipline, only paternal but not maternal aggression predicted supportive attitudes toward wife beating. Analyses separately for each gender however demonstrated that maternal harsh discipline was a significant predictor for girls only, whereas paternal harsh discipline predicted supportive attitudes toward wife beating for boys only, indicating gendered pathways from parental harsh discipline to wife beating attitudes. Based on the theory of intergenerational transmission of violence and of social learning (Bandura, 1977; Kalmuss, 1984), girls may have taken their mother as role model and boys their father. Thus, girls and boys who experienced harsh discipline by the parent of the same sex may have learned from them a unique model of how to deal with conflicts. That means that girls who experienced harsh disciplinary measures by their mothers and boys who experienced harsh disciplinary measures by their fathers (i.e., their primary role models in childhood) may have internalized that violence is an adequate and appropriate way to deal with potential conflict situations. It may also have fed into the false belief that the victim did something wrong and aggression is a useful measure to "correct" behavior. This in turn may explain, at least partly, why girls and boys who experienced maternal or paternal harsh discipline respectively have more justifying attitudes toward wife beating. In line with this idea, previous research has also shown that adolescents who receive corporal punishment will also be less exposed to other non-violent conflict resolving types, and will hence be more 
likely to approve of marital violence as a means of conflict resolution (Straus \& Yodanis, 1996). The influence of socialization is, however, not limited to attitudes and can influence behavior as well, as Straus and Kantor (1994) have demonstrated that corporal punishment in the family of origin during adolescence was associated with a higher likelihood of wife assault.

Finally, moral neutralization of aggression was, as expected, a significant predictor of supportive attitudes toward wife beating. This suggests that the agreement with wife beating may be the result of a wider cognitive process of moral disengagement as proposed by Bandura (2002). Processes such as moral justification, euphemistic labeling, and displacement and diffusion of responsibility seem to make it more likely that wife beating is considered as a necessary and justifiable act to discipline a disobedient wife. Such processes could be used, for example, to justify a man hitting his wife to correct her behavior and better their marriage. Furthermore, higher moral neutralization of aggression may be linked to supportive attitudes toward wife beating because it is a construct that generally excuses the use of violence to solve problems (Ribeaud \& Eisner, 2010).

Overall, our results suggest that patriarchal ideology, social learning, and social cognitions play a key role in understanding supportive attitudes toward wife beating. At the same time, our findings indicate that an integrative framework, opposed to single theories, allows for a broader and more holistic understanding of wife beating attitudes as the factors derived from three theoretical perspectives predicted wife beating attitudes within one model.

\section{Strengths and Limitations}

We believe that our study has several strengths. First, we studied predictors of wife beating attitudes that are based on three theoretical perspectives. As no single theory can completely explain justification of wife beating (Haj-Yahia \& Uysal, 2011; Heise, 1998), we examined theoretically-relevant predictors within an integrative theoretical framework, 
comprising patriarchal ideology, social learning theory, and social cognitions. Second, we followed a gender-inclusive approach examining attitudes toward wife beating among both adolescent girls and boys. This expands the current research body which is primarily based on evidence from all-female adult samples (Boy \& Kulczycki, 2008). Third, we were able to recruit a large adolescent sample from different schools in Amman, Jordan, providing, to our knowledge, evidence for 14- to 16-year-olds from a MENA country for the first time.

At the same time, several limitations have to be acknowledged. First, the findings are based on a cross-sectional survey. This means that there are significant limits on the scope to which the relationship between the dependent variable and the predictors can be determined. Hence, longitudinal data is required to clarify the causal relations. Second, the sample of this study was purposely chosen and not random, comprising a higher proportion of middle-class students who go to private schools in Amman, the capital city. Thus, the results may not be generalizable to all high school students in Jordan. Future research should aim to study random and/or representative samples in both urban and rural areas. Third, the scales on beliefs regarding control of female sexuality, religiosity, and parental harsh discipline were created by the authors for this study and/or adopted from previous research which means that they have not been psychometrically validated. Particularly, construct validity of these measures should be examined in future research. Nonetheless, face validity and acceptable to good reliability were established. Fourth, it should be noted that the current study considered attitudes and not behavioral intentions or actual behavior. We would anticipate that attitudes in support of wife beating during adolescence increase the chance of perpetrating such aggression over the life course. However, testing this would require longitudinal data which was outside the scope of this study. Fifth, as the study included sensitive topics, responses may have been affected by a tendency to social desirability. To minimize this potential bias, we assured anonymity and confidentiality to all of our participants. 


\section{Implications for Research, Policy, and Intervention}

The current study presented data on boys' and girls' attitudes toward wife beating in Jordan for the first time. Given that adolescence is a sensitive period for forming attitudes and these attitudes may predict future behavior, studying this age group is of particular importance. For future research, it would be valuable to conduct longitudinal studies beginning in late childhood to examine causal relationships as well as the temporal stability of these attitudes.

Our findings also highlight the necessity to put the issue of violence against women in general and supportive wife beating attitudes in particular on policy agendas in Jordan. Although Jordan implemented laws against domestic violence and ratified the Convention on the Elimination of all Forms of Discrimination against Women (CEDAW), there are several gaps in the legal protection of women (Amnesty International, 2018). Hence, effective legal measures are needed to guarantee women's rights and protect them from all forms of violence. In addition, corporal punishment of children is still lawful in homes in Jordan (Global Initiative to End All Corporal Punishment of Children, 2018). Given that harsh parental discipline and child maltreatment are associated with supportive wife beating attitudes and wife assault, as demonstrated in the current study as well as in previous research (e.g., Dalal et al., 2012; Haj-Yahia \& Uysal, 2008; Straus \& Kantor, 1994), a legal framework that prohibits corporal punishment in homes should be established (see also Global Initiative to End All Corporal Punishment of Children, 2018).

Beyond legal measures, the implementation of effective evidence-based intervention programs is sorely needed, aiming to reduce the acceptance of wife beating and, hopefully, at a longer term the substantial rates of violence against women in intimate relationships. In the present study, parental harsh discipline predicted more supportive attitudes toward wife beating. Based on this finding, intervention strategies should focus on the prevention of child 
maltreatment. To address this issue, numerous intervention programs have been developed, mostly in the U.S. and other Western high-income countries. Promising effects have been found for the following types of intervention: (1) early childhood home visiting to educate and provide support for parents, (2) parent education programs, (3) prevention of abusive head trauma, and (4) multi-component programs, which typically cover preschool education, family support, parenting skills, and child care (for a systematic review of reviews, see Mikton \& Butchart, 2009). Implementing these types of interventions may reduce parental harsh discipline and, in turn, supportive attitudes toward wife beating. However, as most interventions have been evaluated in Western countries, it is still unclear to which extent these findings can be generalized to non-Western countries (cf., Heise, 2011).

In addition, interventions may target honor beliefs, including the deconstruction of beliefs regarding control of female sexuality, and, at the societal level, social norms that condone violence against women. Despite the importance of this topic, there are only few evaluated intervention studies that aimed to challenge social and cultural norms condoning violence against women, revealing mixed results (Heise, 2011). Helms (2015) has developed a four-component counseling tool for professionals to target issues of honor and shame. The efficacy of this tool has, however, not been tested yet. Hence, the development and evaluation of interventions addressing beliefs regarding control of female sexuality and honor-related beliefs is of great importance. 


\section{References}

Akyüz, A., Yavan, T., Şahiner, G., \& Kılıç, A. (2012). Domestic violence and woman's reproductive health: A review of the literature. Aggression and Violent Behavior, 17, 514-518. doi:10.1016/j.avb.2012.07.005

Al-Badayneh, D. M. (2012). Violence against women in Jordan. Journal of Family Violence, 27, 369-379. doi:10.1007/s10896-012-9429-1

Al-Modallal, H., Zayed, I. A., Abujilban, S., Shehab, T., \& Atoum, M. (2015). Prevalence of intimate partner violence among women visiting health care centers in Palestine refugee camps in Jordan. Health Care for Women International, 36, 137-148.

doi:10.1080/07399332.2014.948626

Al-Nsour, M., Khawaja, M., \& Al-Kayyali. (2009). Domestic violence against women in Jordan: Evidence from health clinics. Journal of Family Violence, 24, 569-575. doi:10.1007/s10896-009-9255-2

Ali, P. A., \& Naylor, P. B. (2013). Intimate partner violence: A narrative review of the feminist, social and ecological explanations for its causation. Aggression and Violent Behavior, 18, 611-619. doi:10.1016/j.avb.2013.07.009

Alzoubi, F. A., \& Ali, R. A. (2018). Jordanian men's and women's attitudes toward intimate partner violence and its correlates with family functioning and demographics. Journal of Interpersonal Violence. Advance online publication. doi:10.1177/0886260518769368 Amnesty International (2018). Amnesty International report 2017/18: The state of the world's human rights. Retrieved from www.amnesty.org/en/documents/pol10/6700/2018/en/ Bandura, A. (1977). Social learning theory. Englewood Cliffs, N.J.: Prentice Hall.

Bandura, A. (2002). Selective moral disengagement in the exercise of moral agency. Journal of Moral Education, 31, 101-119. doi:10.1080/0305724022014322 
Barriga, A. Q., \& Gibbs, J. C. (1996). Measuring cognitive distortion in antisocial youth: Development and preliminary validation of the "How I Think" questionnaire. Aggressive Behavior, 22, 333-343. doi:10.1002/(SICI)1098-2337(1996)22:5<333::AID$\mathrm{AB} 2>3.0 . \mathrm{CO} ; 2-\mathrm{K}$

Boy, A., \& Kulczycki, A. (2008). What we know about intimate partner violence in the Middle East and North Africa. Violence against Women, 14, 53-70. doi:10.1177/1077801207311860

Crittenden, C. A., \& Wright, E. M. (2013). Predicting patriarchy: Using individual and contextual factors to examine patriarchal endorsement in communities. Journal of Interpersonal Violence, 28, 1267-1288. doi:10.1177/0886260512468245

Dalal, K., Lee, M. S., \& Gifford, M. (2012). Male adolescents' attitudes toward wife beating: A multi-country study in South Asia. Journal of Adolescent Health, 50, 437-442. doi:10.1016/j.jadohealth.2011.09.012

Department of Statistics, \& ICF International (2013). Jordan Population and Family Health Survey 2012. Retrieved from https://dhsprogram.com/publications/publication-FR282$\underline{\text { dhs-final-reports.cfm }}$

Dhaher, E. A., Mikolajczyk, R. T., Maxwell, A. E., \& Krämer, A. (2010). Attitudes toward wife beating among Palestinian women of reproductive age from three cities in West Bank. Journal of Interpersonal Violence, 25, 518-537. doi:10.1177/0886260509334409

Douki, S., Nacef, F., Belhadj, A., Bouasker, A., \& Ghachem, R. (2003). Violence against women in Arab and Islamic countries. Archives of Women's Mental Health, 6, 165-171. doi:10.1007/s00737-003-0170-X

Duyan, V., \& Duyan, G. (2005). Turkish social work students' attitudes toward sexuality. Sex Roles, 52, 697-706. doi:10.1007/s11199-005-3736-4 
Eisner, M., \& Ghuneim, L. (2013). Honor killing attitudes amongst adolescents in Amman, Jordan. Aggressive Behaviour, 9999, 1-13. doi:10.1002/ab.21485

Ellonen, N., \& Pösö, T. (2011). Children's experiences of completing a computer-based violence survey: Ethical implications. Children and Society, 25, 470-481. doi:10.1111/j.1099-0860.2010.00292.x

FRA - European Union Agency for Fundamental Rights (2015). Violence against women: An EU-wide survey. Luxembourg: Publications Office of the European Union. Retrieved from https://fra.europa.eu/en/publication/2014/violence-against-women-eu-wide-surveymain-results-report

Global Initiative to End All Corporal Punishment of Children (2018). Corporal punishment of children in Jordan. Retrieved from http://www.endcorporalpunishment.org/wpcontent/uploads/country-reports/Jordan.pdf

Haj-Yahia, M. M. (1998a). A patriarchal perspective of beliefs about wife beating among Palestinian men from the West Bank and the Gaza Strip. Journal of Family Issues, 19, 595-621. doi:10.1177/019251398019005006

Haj-Yahia, M. M. (1998b). Beliefs about wife beating among Palestinian women: The influence of their patriarchal ideology. Violence Against Women, 4, 533-558. doi:10.1177/1077801298004005002

Haj-Yahia, M. M. (2002). Beliefs of Jordanian women about wife-beating. Psychology of Women Quarterly, 26, 282-291. doi: 10.1111/1471-6402.t01-1-00067

Haj-Yahia, M. M. (2003). Beliefs about wife beating among Arab men from Israel: The influence of their patriarchal ideology. Journal of Family Violence, 18, 193-206. doi:10.1023/A:1024012229984 
Haj-Yahia, M. M. (2005). Can people's patriarchal ideology predict their beliefs about wife abuse? The case of Jordanian men. Journal of Community Psychology, 33, 545-567. doi:10.1002/jcop.20068

Haj-Yahia, M. M., \& Btoush, R. (2018). Attitudes of Palestinians toward social work interventions in cases of wife assault. Violence Against Women, 24, 603-626. doi:10.1177/1077801217708886

Haj-Yahia, M. M., Sousa, C., Alnabilsy, R., \& Elias, H. (2015). The influence of Palestinian physicians' patriarchal ideology and exposure to family violence on their beliefs about wife beating. Journal of Family Violence, 30, 263-276. doi:10.1007/s10896-015-9671-4

Haj-Yahia, M. M., \& Uysal, A. (2008). Beliefs about wife beating among medical students from Turkey. Journal of Family Violence, 23, 119-133. doi:10.1007/s10896-007-9134-7

Haj-Yahia, M. M., \& Uysal, A. (2011). Toward an integrative theoretical framework for explaining beliefs about wife beating: A study among students of nursing from Turkey. Journal of Interpersonal Violence, 26, 1401-1431. doi:10.1177/0886260510369135

Hambleton, R. K., \& Kanjee, A. (1995). Increasing the validity of cross-cultural assessments: Use of improved methods for test adaptations. European Journal of Psychological Assessment, 11, 147-157. doi:10.1027/1015-5759.11.3.147

Hayes, A. F. (2017). Introduction to mediation, moderation, and conditional process analysis: A regression-based approach (2nd ed.). New York, NY: Guilford Press.

Heise, L. L. (1998). Violence against women: An integrated, ecological framework. Violence against Women, 4, 262-290. doi:10.1177/1077801298004003002

Heise, L. L. (2011). What works to prevent partner violence? An evidence overview. Retrieved from https://www.oecd.org/derec/49872444.pdf 
Heise, L., Ellsberg, M., \& Gottmoeller, M. (2002). A global overview of gender-based violence. International Journal of Gynecology \& Obstetrics, 78, 5-14. doi:10.1016/S0020-7292(02)00038-3

Helms, B. L. (2015). Honour and shame in the Canadian Muslim community: Developing culturally sensitive counselling interventions. Canadian Journal of Counseling and Psychotherapy, 49, 163-184.

Herrenkohl, T. I., Huang, B., Tajima, E. A., \& Whitney, S. D. (2003). Examining the link between child abuse and youth violence: An analysis of mediating mechanisms. Journal of Interpersonal Violence, 18, 1189-1208. doi:10.1177/0886260503255558

Kalmuss, D. (1984). The intergenerational transmission of marital aggression. Journal of Marriage and Family, 46, 11-19. doi:10.2307/351858

Krakow, M. M., Jensen, J. D., Carcioppolo, N., Weaver, J., Liu, M., \& Guntzviller, L. M. (2015). Psychosocial predictors of human papillomavirus vaccination intentions for young women 18 to 26: Religiosity, morality, promiscuity, and cancer worry. Women's Health Issues, 25, 105-111. doi:10.1016/j.whi.2014.11.006

Kroger, J. (2007). Identity development: Adolescence through adulthood (2nd ed.). Thousand Oaks, CA: Sage.

Kulwicki, A. D. (2002). The practice of honor crimes: A glimpse of domestic violence in the Arab world. Issues in Mental Health Nursing, 23, 77-87. doi:10.1080/01612840252825491

Lowe, M., Khan, R., Thanzami, V., Barzy, M., \& Karmaliani, R. (2018). Attitudes toward intimate partner honor-based violence in India, Iran, Malaysia and Pakistan. Journal of Aggression, Conflict and Peace Research. doi:10.1108/jacpr-09-2017-0324 
McKee, L., Roland, E., Coffelt, N., Olson, A. L., Forehand, R., Massari, C., ... Zens, M. S. (2007). Harsh discipline and child problem behaviors: The roles of positive parenting and gender. Journal of Family Violence, 22, 187-196. doi:10.1007/s10896-007-9070-6

Mikton, C., \& Butchart, A. (2009). Child maltreatment prevention: A systematic review of reviews. Bulletin of the World Health Organization, 87, 353-361. doi:10.2471/BLT.08.057075

Nuffic (2017). Education system Jordan described and compared with the Dutch system. Retrieved from https://www.nuffic.nl/en/subjects/education-and-diplomas-jordan/

Oberwittler, D., \& Kasselt, J. (2014). Honor killings. In R. Gartner \& B. McCarthy (Eds.), The Oxford handbook on gender, sex, and crime (pp. 383-399). Oxford, UK: Oxford University Press.

O’Leary, K. D. (1988). Physical aggression between spouses: A social learning theory perspective. In V. B. Van Hasselt, R. L. Morrison, A. S. Bellack, \& M. Hersen (Eds.), Handbook of Family Violence. Boston, MA: Springer.

Obeid, N., Chang, D. F., \& Ginges, J. (2010). Beliefs about wife beating: An exploratory study with Lebanese students. Violence Against Women, 16, 691-712. doi:10.1177/1077801210370465

Ribeaud, D., \& Eisner, M. (2010). Are moral disengagement, neutralization techniques, and self-serving cognitive distortions the same? Developing a unified scale of moral neutralization of aggression. International Journal of Conflict and Violence, 4, 298-315. doi:10.4119/UNIBI/IJCV.92

Rossano, M. J. (2008). The moral faculty: Does religion promote "moral expertise"? International Journal for the Psychology of Religion, 18, 169-194. doi:10.1080/10508610802115727 
Saunders, D. G., Lynch, A. B., Grayson, M., \& Linz, D. (1987). The inventory of beliefs about wife beating: The construction and initial validation of a measure of beliefs and attitudes. Violence and Victims, 2, 39-57.

Schuster, I., \& Krahé, B. (2019). Predictors of sexual aggression perpetration among male and female college students: Cross-cultural evidence from Chile and Turkey. Sexual Abuse, 31, 318-343. doi:10.1177/1079063218793632

Smith, S. J. (2015). Risky sexual behavior among young adult Latinas: Are acculturation and religiosity protective? The Journal of Sex Research, 52, 43-54. doi:10.1080/00224499.2013.821443

Spencer, R. A., Shahrouri, M., Halasa, L., Khalaf, I., \& Clark, C. J. (2014). Women's help seeking for intimate partner violence in Jordan. Health Care for Women International, 35, 380-399. doi:10.1080/07399332.2013.815755

Straus, M. A., \& Kantor, G. K. (1994). Corporal punishment of adolescents by parents: A risk factor in the epidemiology of depression, suicide, alcohol abuse, child abuse, and wife beating. Adolescence, 29, 543-561.

Straus, M. A., \& Yodanis, C. L. (1996). Corporal punishment in adolescence and physical assaults on spouses in later life: What accounts for the link? Journal of Marriage \& Family, 58, 825-841. doi: 10.2307/353973

Sykes, G. M., \& Matza, D. (1957). Techniques of neutralization: A theory of delinquency. American Sociological Review, 22, 664-670. doi:10.2307/2089195

United Nations Development Programme (2018). Human development indices and indicators: 2018 statistical update. Retrieved from www.hdr.undp.org/en/content/human-development-indices-indicators-2018-statisticalupdate 
Vandello, J. A., \& Cohen, D. (2008). Culture, gender, and men's intimate partner violence. Social and Personality Psychology Compass, 2, 652-667. doi:10.1111/j.17519004.2008.00080.x

WHO (2013). Global and regional estimates of violence against women: Prevalence and health effects of intimate partner violence and non-partner sexual violence. Retrieved from http://www.who.int/reproductivehealth/publications/violence/9789241564625/en/

Yllö, K. A., \& Straus, M. A. (1990). Patriarchy and violence against wives: The impact of structural and normative factors. In M. A. Straus \& R. J. Gelles (Eds.), Physical violence in American families (pp. 383-399). New Brunswick: Transaction.

Zaatut, A., \& Haj-Yahia, M. M. (2016). Beliefs about wife beating among Palestinian women from Israel: The effect of their endorsement of patriarchal ideology. Feminism and Psychology, 26, 405-425. doi:10.1177/0959353516647071 
Table 1

Prevalence of Agreement (Agree/Strongly Agree) in Percentages and Gender Differences in Attitudes toward Wife Beating

\begin{tabular}{|c|c|c|c|c|}
\hline Item & $\begin{array}{r}\text { Total } \\
\text { sample }\end{array}$ & Girls & Boys & $\chi^{2}$ \\
\hline $\begin{array}{l}\text { A husband has the right to beat his wife if she continues } \\
\text { reminding him of his weak points. }\end{array}$ & 8.9 & 5.1 & 13.3 & $17.48^{* * *}$ \\
\hline Sometimes it is $\mathrm{OK}$ for a man to beat his wife. & 6.1 & 2.2 & 10.5 & $25.54 * * *$ \\
\hline $\begin{array}{l}\text { If a wife lies to her husband, he is justified in beating } \\
\text { her. }\end{array}$ & 12.5 & 7.1 & 18.5 & $25.25 * * *$ \\
\hline There is no excuse for a man to beat his wife. ${ }^{a}$ & 30.5 & 25.8 & 35.8 & $9.89 * *$ \\
\hline $\begin{array}{l}\text { Occasional violence by a husband toward his wife can } \\
\text { help maintain the marriage. }\end{array}$ & 13.5 & 9.2 & 18.4 & $15.12 * * *$ \\
\hline $\begin{array}{l}\text { Even when a wife's behavior challenges her husband's } \\
\text { manhood, he is not justified in beating her. }{ }^{\text {a }}\end{array}$ & 30.9 & 29.0 & 33.0 & 1.56 \\
\hline $\begin{array}{c}\text { A husband has no right to beat his wife, even if she } \\
\text { breaks agreements she has made with him. }{ }^{\text {a }}\end{array}$ & 27.8 & 24.4 & 31.6 & 5.46 \\
\hline An unfaithful wife deserves to be beaten. & 50.5 & 43.3 & 58.6 & $19.70 * * *$ \\
\hline $\begin{array}{l}\text { A husband has the right to beat his wife if she doesn't } \\
\text { respect his parents or siblings. }\end{array}$ & 17.7 & 9.4 & 27.1 & $45.17 * * *$ \\
\hline $\begin{array}{l}\text { A husband has the right to beat his wife if she doesn't } \\
\text { respect his relatives. }\end{array}$ & 10.7 & 5.2 & 17.0 & $30.38^{* * *}$ \\
\hline $\begin{array}{l}\text { A husband has the right to beat his wife if she insults } \\
\text { him in front of his friends. }\end{array}$ & 21.4 & 13.8 & 30.1 & $33.20 * * *$ \\
\hline $\begin{array}{l}\text { A woman who fails to meet the expectations of her } \\
\text { husband deserves to be beaten. }\end{array}$ & 7.3 & 4.0 & 11.0 & $15.39 * * *$ \\
\hline $\begin{array}{l}\text { A husband has the right to beat his wife if she constantly } \\
\text { disobeys him. }\end{array}$ & 22.1 & 13.5 & 31.8 & $41.26^{* * *}$ \\
\hline
\end{tabular}

Note: ${ }^{a}$ Percentages of disagreement (disagree/strongly disagree) are reported. Alpha-level corrected for multiple comparisons: $* * p<.004(.05 / 13), * * * p<.001$. 
Table 2

Mean Scores and Bivariate Correlations of the Study Variables

\begin{tabular}{|c|c|c|c|c|c|c|c|c|c|c|}
\hline Scale & Range & $\begin{array}{l}M_{\text {Total }} \\
(S D)\end{array}$ & $\begin{array}{c}M_{\text {Girls }} \\
(S D)\end{array}$ & $\begin{array}{c}M_{\text {Boys }} \\
(S D)\end{array}$ & 1 & 2 & 3 & 4 & 5 & 6 \\
\hline $\begin{array}{l}\text { 1. Attitudes toward wife } \\
\text { beating }\end{array}$ & $1-7$ & $\begin{array}{c}3.16 \\
(1.24)\end{array}$ & $\begin{array}{c}2.73 * * * \\
(1.06)\end{array}$ & $\begin{array}{c}3.65 * * * \\
(1.24)\end{array}$ & - & $.33 * * *$ & .04 & $.11 * *$ & $.24 * * *$ & $.29 * * *$ \\
\hline $\begin{array}{l}\text { 2. Beliefs regarding control } \\
\text { of female sexuality }\end{array}$ & $1-4$ & $\begin{array}{c}2.49 \\
(0.81)\end{array}$ & $\begin{array}{l}2.41 * * \\
(0.74)\end{array}$ & $\begin{array}{l}2.59 * * \\
(0.88)\end{array}$ & & - & $.22 * * *$ & -.02 & -.01 & -.01 \\
\hline 3. Religiosity & $1-4$ & $\begin{array}{c}3.07 \\
(0.48)\end{array}$ & $\begin{array}{c}3.09 \\
(0.46)\end{array}$ & $\begin{array}{l}3.05 \\
(0.50)\end{array}$ & & & - & $-.09 *$ & $-.06^{\dagger}$ & $-.18 * * *$ \\
\hline 4. Maternal harsh discipline & $1-5$ & $\begin{array}{c}2.06 \\
(0.82)\end{array}$ & $\begin{array}{c}2.07 \\
(0.82)\end{array}$ & $\begin{array}{l}2.05 \\
(0.82)\end{array}$ & & & & - & $.54 * * *$ & .02 \\
\hline 5. Paternal harsh discipline & $1-5$ & $\begin{array}{c}2.03 \\
(0.91)\end{array}$ & $\begin{array}{c}1.80 * * * \\
(0.79)\end{array}$ & $\begin{array}{c}2.28 * * * \\
(0.97)\end{array}$ & & & & & - & $.14 * * *$ \\
\hline $\begin{array}{l}\text { 6. Moral neutralization of } \\
\text { aggression }\end{array}$ & $1-4$ & $\begin{array}{c}2.15 \\
(0.52)\end{array}$ & $\begin{array}{c}1.97 * * * \\
(0.44)\end{array}$ & $\begin{array}{c}2.35 * * * \\
(0.53)\end{array}$ & & & & & & - \\
\hline
\end{tabular}

Note: Significance level of gender differences and correlation coefficients: ${ }^{\dagger} p<.10,{ }^{*} p<.05, * * p<.01, * * * p<.001$. 
Table 3

Hierarchical Regression Analyses of Attitudes toward Wife Beating $(N=821)$

\begin{tabular}{lccc}
\hline & $\begin{array}{c}\text { Complete } \\
\text { sample }\end{array}$ & \multicolumn{2}{c}{$\begin{array}{c}\text { Analysis by } \\
\text { gender }\end{array}$} \\
\cline { 2 - 4 } Predictor variable & $B$ & $B_{\text {Girls }}$ & $B_{\text {Boys }}$ \\
\hline Step 1 & $(S E)$ & $(S E)$ & $(S E)$ \\
Gender $(0=$ female, $1=$ male $)$ & $0.94^{* * *}$ & & \\
& $(.07)$ & & \\
Parental education & $-0.14^{* * *}$ & $-.16^{* * *}$ & $-.13^{* * *}$ \\
& $(.02)$ & $(.02)$ & $(.03)$ \\
Family size $(0=$ small & $0.38^{* * *}$ & $.33^{* *}$ & $.45^{* * *}$ \\
$\quad$ family, $1=$ large family) & $(.08)$ & $(.10)$ & $(.13)$ \\
Traditional family structure $(0=$ non- & $0.26^{* *}$ & $.28^{*}$ & .25 \\
$\quad$ traditional, $1=$ traditional $)$ & $(.10)$ & $(.12)$ & $.16)$ \\
$R^{2} \quad .27^{* * *}$ & $.17^{* * *}$ & $.14^{* * * *}$
\end{tabular}

\section{Step 2}

Gender $(0=$ female, $1=$ male $)$ $0.66^{* * *}$

Parental education

$$
-0.12 * * *
$$

Family size $(0=$ small

$0.27 * * *$

$-0.10 * *$

family, 1 = large family)

(.08)

$0.17^{\dagger}$

Traditional family structure $(0=$ non-

$0.19^{*}$

(.10)

$0.22 *$

(.09)

(.11)

(.03) traditional, $1=$ traditional)

$0.34 * * *$

Beliefs regarding control of

(.05)

female sexuality

Religiosity

0.05

$0.41 * * *$

(.07)

$-0.01$

(.08)

(.10)

Maternal harsh discipline

0.05

$0.21 * *$

(.05)

$0.12 *$

$(.07)$

Paternal harsh discipline

(.05)

Moral neutralization of aggression

$\begin{array}{cc}0.40 * * * & 0.35^{* *} \\ (.08) & (.10)\end{array}$

$0.37 * *$

(.12)

0.17

(.15)

$0.31 * * *$

(.07)

0.10

(.12)

$-0.13$

0.01

$0.22 * *$

$0.44 * * *$ 


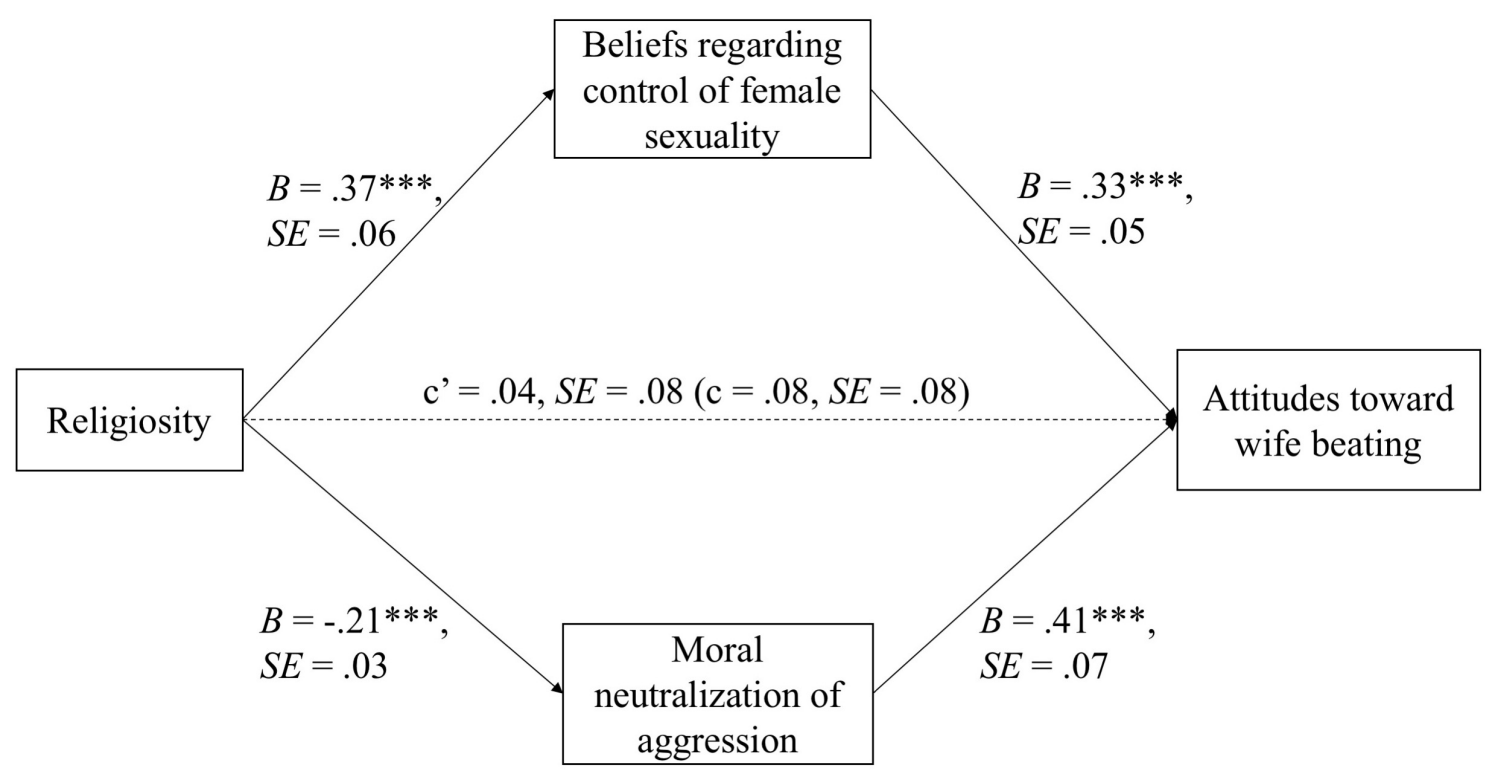

Figure 1. Path model, controlled for gender, parental education, family size, and traditional family structure $(N=826) .{ }^{* * *} p<.001$. 